\title{
Need satisfaction and need frustration as distinct and potentially co-occurring constructs: Need profiles examined in physical education and sport
}

\author{
Victoria E. Warburton ${ }^{1}$ D $\cdot$ John C. K. Wang ${ }^{2} \cdot$ Kimberley J. Bartholomew $^{1} \cdot$ Rebecca L. Tuff $^{1} \cdot$ Krystal C. M. Bishop $^{1}$
}

Published online: 19 September 2019

(c) The Author(s) 2019

\begin{abstract}
We explored the combined relationships between need satisfaction and need frustration and their simultaneous associations with motivation, well-being, and ill-being. Data from two cross-sectional samples that represent different physical activity contexts, physical education ( $\mathrm{N}=274 ; \mathrm{M}_{\text {age }}=14.18 \pm 1.42$ years) and leisure-time sport $\left(\mathrm{N}=160 ; \mathrm{M}_{\text {age }}=22.98 \pm 8.79\right.$ years $)$, are reported. The identification of distinctive subgroups (need profiles) which had unique associations with motivation, wellbeing, and ill-being provided evidence for the distinct, yet co-occurring nature of need satisfaction and need frustration and the asymmetrical relationship between need satisfaction and need frustration. Our results suggest that experiencing need satisfaction without need frustration was the most adaptive need profile. Experiences of need satisfaction partly countered the effects of need frustration on motivation, well-being, and ill-being. The current study enhances our understanding of people's psychological need experiences, motivation, and psychological health though highlighting the importance of examining need satisfaction and need frustration in combination rather than isolation.
\end{abstract}

Keywords Profiles $\cdot$ Need satisfaction $\cdot$ Need frustration $\cdot$ Physical education $\cdot$ Sport

\section{Introduction}

Research grounded in Basic Psychological Need Theory (BPNT, Deci and Ryan 1985; Ryan and Deci 2002) has increasingly focused on both the bright and dark sides of the three basic psychological needs, exploring their simultaneous associations with motivation and psychological functioning (Haerens et al. 2015; Ryan and Deci 2000). The more recent emphasis on the dark motivational pathway stemmed from the identification of need satisfaction and need frustration as distinct constructs with specific antecedents and outcomes (Bartholomew et al. 2011a, b; Vansteenkiste and Ryan 2013). Consequently, it is possible that one can experience both the satisfaction and frustration of the three psychological needs within the same environment

Victoria E. Warburton

V.Warburton@uea.ac.uk

1 School of Education and Lifelong Learning, University of East Anglia, Norwich, Norfolk NR4 7TJ, UK

2 National Institute of Education, Nanyang Technological University, Nanyang, Singapore
(Bartholomew et al. 2011b). It is, therefore, important to examine the combined relations between these distinct but potentially co-occurring constructs. In this paper we sought to address this fundamental and understudied issue through examining perceived 'need profiles' and their relations with motivation and psychological functioning in two contrasting physical activity contexts, compulsory physical education (PE) and voluntary leisure-time sport.

\section{Basic psychological needs and the motivational pathways}

Basic Psychological Need Theory, one of six mini theories in Self-Determination Theory (SDT), suggests that three basic psychological needs for autonomy (feeling volitional), competence (feeling effective), and relatedness (feeling connected) are essential for human functioning and development (Deci and Ryan 2000). The theory proposes that when the social environment supports these three basic psychological needs, individuals will experience need satisfaction, autonomous motivation, optimal functioning, and psychological growth (bright motivational pathway). Whereas when the social environment thwarts these needs, individuals will 
experience need frustration, controlled motivation, nonoptimal functioning and psychological ill-health (dark motivational pathway). Thus, experiences of need satisfaction and need frustration can directly influence an individuals' motivation and functioning. Autonomous motivation and well-being occur when autonomy, competence, and relatedness needs are satisfied and individuals engage in activities because they enjoy them or find them inherently interesting (i.e., intrinsic motivation) or valuable (i.e., identified regulation; e.g., Markland and Tobin 2010; Milyavskaya and Koestner 2011). Controlled motivation and ill-being occur when the three psychological needs are frustrated and individuals engage in activities purely to gain rewards or avoid punishments (i.e., external regulation) or escape feelings of guilt or shame and attain feelings of worth (i.e., introjected regulations; e.g., Bartholomew et al. 2018; Haerens et al. 2015). Need frustration has also been associated with 'giving up' and a complete lack of an intention to act (i.e., amotivation; Bartholomew et al. 2018).

Research exploring the bright pathway has been prolific with substantial evidence accumulating across multiple life domains, including sport, (Adie et al. 2008), education (Reeve and Jang 2006), health (Halvari et al. 2013) work (Van den Broeck et al. 2010), and interpersonal relationships (Patrick et al. 2007). Within this pathway experiences of need satisfaction, whereby individuals feel they are good at what they do, connected to those around them, and free to make decisions and choose a course of action, have consistently predicted autonomous motivation and psychological and physical well-being (e.g., Milyavskaya and Koestner 2011; Mouratidis et al. 2011; Williams et al. 2011). However, despite this strength of evidence for the brighter motivational pathway, early work on the darker motivational pathway was less convincing. Initially, non-optimal functioning and the darker motivational pathway was explored through examining low levels of need satisfaction. However, research findings were equivocal, with the strength of associations between low need satisfaction and indices of ill-being, at best, being weak, and in some cases completely absent (Adie et al. 2008; Quested and Duda 2010). These findings led to the suggestion that the psychological needs are more influential for optimal than non-optimal functioning (Adie et al. 2008; Quested and Duda 2010).

\section{Low need satisfaction and need frustration}

Given the potential explanatory role of basic psychological needs in non-optimal motivation and even severe maladjustment, a conceptual extension of the theory was necessary. Researchers argued that low scores on measures of need satisfaction did not relate robustly to indices of malfunctioning because they did not adequately capture the intensity of feeling characterized by experiences of need frustration
(Bartholomew et al. 2011b; Ryan et al. 2016). For instance, individuals who experience low need satisfaction may report feelings of not having as many choices as they would like, not being supported by others, and not being very good at something. Whereas an individual who experiences need frustration would report feelings of being pushed or forced into activities, rejected or excluded from a group, and of being heavily criticized. Whilst low levels of need satisfaction may be associated with less vitality and excitement for physical activity, experiences of need frustration are more likely to be associated with controlled motivation, amotivation and even burnout and other pathological behaviors amongst individuals in these settings. Thus, a distinction needed to be made between a lack of need satisfaction and experiences of need frustration. The differences in the intensity of feelings that conceptually distinguish between the two constructs has led to the suggestion that they may be best viewed as asymmetrical, in that low need satisfaction does not necessarily involve need frustration but need frustration does involve experiences of low need satisfaction (Vansteenkiste and Ryan 2013).

Initial work establishing need satisfaction and need frustration as distinct constructs was conducted in the sport domain (Bartholomew et al. 2011a, b). In their research, Bartholomew et al. (2011b), were able to provide support for the distinctiveness of need satisfaction and need frustration through developing, validating, and testing a measure of psychological need frustration. Initial support for the incremental predictive validity of the need frustration subscales was also provided in that need frustration accounted for additional variance in vitality and exhaustion above and beyond that due to need satisfaction. As expected, need frustration added especially to the prediction of exhaustion, the negative outcome. Moreover, further support for the utility of considering need frustration at both betweenand within-person levels was provided in a second paper by Bartholomew et al. (2011a). Across three separate samples, they simultaneously examined both the bright and dark motivational pathways. Athletes' perceptions of need satisfaction were more strongly related to positive outcomes such as vitality and positive affect, whereas their experiences of need frustration more consistently predicted maladaptive outcomes such as disordered eating, burnout, depression, and perturbed physiological arousal.

Evidence for the factorial validity of need frustration as distinct from need satisfaction has also been evidenced in the development of additional measures that capture both need experiences at the general domain level rather than the domain specific level, for example the Balanced Measurement of Psychological Needs scale (Sheldon and Hilpert 2012) and the Basic Psychological Need Satisfaction and Frustration scale (Chen et al. 2015). It has been demonstrated that this distinction was not simply due to effects 
associated with the positive (satisfaction) versus negative (frustration) scale items (Costa et al. 2014). Moreover, the predictive validity of need frustration in terms of the robust relations between need frustration and controlled motivation and maladaptive outcomes, such as negative affect (Stebbings et al. 2012; Teixeria et al. 2018), exhaustion (Bartholomew et al. 2014; Stebbings et al. 2012), disengagement (Jang et al. 2016), depressive symptoms (Chen et al. 2015), compromised relational functioning (Costa et al. 2014), and psychological distress (Teixeria et al. 2018), have been consistently exhibited across multiple contexts including health (Halvari et al. 2017), work (Olafsen et al. 2017), interpersonal relationships (Costa et al. 2014), exercise (Teixeria et al. 2018), compulsory physical education (Haerens et al. 2015) and voluntary sport (Bartholomew et al. 2011a, b). The distinct role of need frustration has also been found in studies using longitudinal (Jang et al. 2016) and diary designs (Mabbe et al. 2018; Van der Kaap-Deeder et al. 2019) and it is proposed that need frustration may represent a critical transdiagnostic process, that helps to explain the covariation between different forms of problem behaviour (Campbell et al. 2018). The emergence of need frustration as both conceptually and empirically distinct from low need satisfaction has provided a more nuanced understanding of both optimal and non-optimal functioning. However, we know little about the combined relations between these distinct but potentially co-occurring constructs and their resulting associations with positive and negative outcomes.

\section{Need profiles}

Observations of physical activity environments often reveal mixed patterns of positive and negative events (Smoll and Smith 2002). These events may have the potential to facilitate feelings of both need satisfaction and need frustration which may, in turn, be simultaneously associated with motivation and psychological health. This was alluded to in the work of Bartholomew et al. (2011a), for example, when the need for autonomy was highly frustrated, greater autonomy satisfaction was related to less exhaustion, whereas when autonomy frustration was lower, satisfaction was not associated with exhaustion. It appears that there may simultaneous effects of need satisfaction and need frustration on the outcomes experienced by individuals. Indeed, in the exercise setting need satisfaction, due to its associations with autonomous motivation, was found to have a small protective effect against the negative effects of need frustration on psychological well-being, suggesting that there may be an optimal need satisfaction and need frustration profile (Teixeira et al. 2018). However, since these studies and much of the research on need satisfaction and need frustration carried out to date has taken a variable-centered approach, our understanding of the concomitant associations of need frustration and need satisfaction with motivation and psychological health is limited.

Over the last 20 years, person-centered approaches have increased in popularity due to their contribution to both our theoretical and practical understanding of motivation (e.g., Haerens et al. 2018; Ntoumanis 2002; Vansteenkiste et al. 2009; Wang and Biddle 2001, Wang et al. 2016). These approaches enable us to explore questions about how motivational constructs combine through identifying specific subgroups with different patterns of relationships to motivational variables, rather than how relationships apply to the average person in the sample (Morin and Wang 2015; Wang et al. 2016). The benefits of employing a person-centered approach to SDT and its constructs is described in previous work in relation to profiles of autonomous and controlled motivation (e.g., Vansteenkiste et al. 2009) and profiles of need supportive and need thwarting behaviours (e.g., Haerens et al. 2018). These can also be applied to profiles of need satisfaction and need frustration given their distinct but co-occurring nature.

Specifically, person-centered approaches provide a test of the distinctiveness of need satisfaction and need frustration depending on the number and combinations of profiles that emerge from the data. If these constructs are distinct, the number of profiles that emerge should be more than just profiles characterized by simple opposites (high-low, low-high). On the other hand, if the constructs are not distinct and instead fall along a single continuum, then a limited number of profiles should emerge since individuals could not perceive need satisfaction and frustration to be simultaneously high or low (Haerens et al. 2018; Vansteenkiste et al. 2009). The use of need profiles will also allow for the proposition of asymmetry between low need satisfaction and need frustration to be empirically tested (Vansteenkiste and Ryan 2013). If, by definition, need frustration must involve low levels of need satisfaction, a high satisfaction-high frustration profile should not emerge. Moreover, with a person-centered approach it is also possible to explore how the combination of experiencing need satisfaction and need frustration within an environment is associated with motivation and psychological health. We can explore the additive and interactive associations of need satisfaction and frustration in relation to optimal and non-optimal functioning (Vansteenkiste et al. 2009). For example, can need frustration be beneficial to an individual, and is this influenced by simultaneous perceptions of need satisfaction which can serve to counter the distinct negative effects of need frustration, or is need frustration universally maladaptive? Exploring these questions is vital if we are to provide a more nuanced theoretical and practical understanding of these key motivational constructs. 


\section{The present study}

The purpose of the present study was to examine withinperson combinations (i.e. profiles) of need satisfaction and need frustration and to examine associations between these profiles and motivation, well-being, and ill-being. We explored this within two physical activity contexts that represented both a compulsory (PE) and voluntary (sport) participation setting. Many people's early experiences of sport and physical activity are within a compulsory PE setting before choosing to engage in voluntary sport later in life. It is, therefore, important to understand people's psychological need experiences and their associated outcomes in both these types of settings. We sought to provide a strong test of the distinctiveness of need satisfaction and need frustration through exploring the emergent profiles in two samples which differed in the extent to which participants could choose to participate in physical activity, a compulsory PE setting and a voluntary leisure-time sport setting. Individuals in a voluntary sport setting may experience less need frustration and more need satisfaction given the optional nature of participation and thus we expected differences in the profile characteristics to emerge in the two samples. Furthermore, compulsory and voluntary physical activity settings offer an important application of the constructs outlined in the introduction because they are environments where both need supports and need thwarts could be salient. Although many teacher/coach behaviors have positive effects on students and athletes, maladaptive teaching and coaching strategies are not altogether uncommon (Bartholomew et al. 2009; Soenens et al. 2012).

We employed a person-centered approach to identify need profiles that represented distinctive subgroups characterized by differences in experiences of need satisfaction and need frustration. It was anticipated, based on the previous research which has established the distinct and co-occurring nature of need satisfaction and need frustration, that two profiles would emerge that were characterized by differences in need satisfaction and need frustration (high-low and low-high). Furthermore, because we hypothesized that need satisfaction and need frustration are distinct constructs, we also anticipated that other profiles may emerge which could be characterized as moderate on one or both of need satisfaction or need frustration. We did not expect a high-high profile to emerge since need satisfaction and need frustration are proposed to be asymmetrical (Vansteenkiste and Ryan 2013).

In addition, we examined whether there were any differences in the associations with optimal (e.g., autonomous motivation, well-being, and enjoyment) and non-optimal functioning (e.g., controlled motivation and burnout) through experiencing different combinations of need satisfaction and need frustration. It was anticipated that the profile characterized as high need satisfaction-low need frustration would be associated with more optimal outcomes, whereas the profile characterized as low need satisfaction-high need frustration would be associated with more non-optimal outcomes. We were also interested in exploring whether the other profiles that emerged would provide evidence to support a protective effect of need satisfaction, in that need satisfaction may offset the negative effects of need frustration to a certain extent. It might be that experiences of need frustration are not universally maladaptive if they are also accompanied by feelings of need satisfaction. Moreover, since we did not expect the sport sample to experience high need frustration due to the voluntary nature of their participation, we were also interested to see whether absolute or relative levels of need frustration were critical to optimal or non-optimal functioning. For example, do individuals who score low on need frustration (i.e., below scale mid-point), but are considered high relative to the rest of the sample in profile analyses, still experience non-optimal functioning?

\section{Method}

\section{Participants}

Two independent samples were collected for the study. Sample 1 consisted of a total of $274 \mathrm{PE}$ students $(n=135$ males; $n=139$ females) from a secondary high school located in the East of England, United Kingdom. The students were aged between 11 to 16 years $(M=14.18, S D=1.42)$ and were in school years 7-11 (Year 7, $n=54$; Year 8, $n=58$; Year 9, $n=58$; Year 10, $n=53$; Year 11, $n=51)$. Although ethnicity data were not formally recorded, the vast majority of students were white. Students were taught in single-sex and mixed ability classes for PE. When data was collected students were participating in activities of athletics, rounders, cricket, and football.

Sample 2 focused on a voluntary leisure-time sport setting and involved 160 athletes $(n=73$ males; $n=87$ females) from community and university sports clubs. The participants were aged between 12 to 55 years $(M=22.98$, $S D=8.79)$ and the majority were White British $(92.5 \%$; Black/Black British 1.9\%; Mixed Parentage 2.5\%; Asian/ Asian British 0.6\%; other ethnicities 2.5\%). They were participating in 14 different sports (individual sports $n=74$; team, $n=86)$ and competed at either club (27.5\%), county (19.4\%), or national (53.1\%) level. Participants had an average of 6.46 years participating in their sport $(S D=5.84)$.

\section{Procedure}

In both samples, ethical approval for the research procedures was obtained from the lead author's institutional body and followed the guidelines of the British Psychological Society. 
In the PE sample, data was collected in the summer term of the school year by a trained research assistant who led the data collection and was available to answer any questions. At the start of a normal curriculum PE lesson, students completed an anonymous multi-section questionnaire, which took approximately $10 \mathrm{~min}$ to complete in quiet classroom conditions. The research assistant was available to support any student with reading the items of the questionnaire.

In the voluntary sport sample, athletes were provided with an anonymous multi-section questionnaire to complete either in person or were emailed the link to an online version, which was created using Smart Survey. The questionnaire took approximately 15 min to complete, with $82.4 \%$ of data collected through the online survey and $17.6 \%$ through completing the paper questionnaire under the supervision of the research assistant. Following the completion of the questionnaire, the participants were informed they could contact the research assistant at any time using the details provided on their information sheet should they have any further questions.

\section{Measures}

Participants completed a multi-section questionnaire that collected the following information. Students and athletes both completed:

Personal details In the PE sample, this section of the questionnaire contained questions related to age, gender, and year group. In the voluntary sport sample, this section contained questions related to age, gender, ethnicity, sport, level of participation, and length of time of participation.

Psychological need satisfaction The degree to which students or athletes experienced satisfaction of the three psychological needs was assessed using 15 items derived from three previously validated questionnaires. The satisfaction of the need for autonomy was assessed using five items (Standage et al. 2003); an example item is 'I have some choice in what I want to do'. The satisfaction of the need for competence was assessed using the five items of the competence subscale within the Intrinsic Motivation Inventory (IMI; McAuley et al. 1989). An example item is 'I think I do pretty well in comparison to other players/ athletes/students'. Finally, the satisfaction of the need for relatedness was assessed using the five item acceptance subscale of the Need for Relatedness Scale (Richer and Vallerand 1998). An example item is 'I feel valued'. In sample 1 all items were preceded by the stem of 'most recently in PE...', while in sample 2 the stem of 'most recently in my sport...' was used. Responses were scored on a seven-point Likert scale which ranged from strongly disagree (1) to strongly agree (7). All subscales have dem- onstrated adequate construct validity and internal reliability in previous research conducted within sport and PE contexts (e.g., Bartholomew et al. 2011a, b; Standage et al. 2003).

Psychological need frustration In both samples the degree to which students or athletes experienced frustration of the three psychological needs was assessed using the 12-item Psychological Need Thwarting Scale (PNTS; Bartholomew et al. 2011b). Four items assessed each subscale and were measured on a seven-point Likert scale, ranging from strongly disagree (1) to strongly agree (7). In sample 1, the items were modified for the PE context and preceded by the stem 'in a PE lesson...' Example items for each subscale are, 'I feel prevented from making choices with regards to the way I learn', (Autonomy), 'There are situations where I am made to feel I am not very good at PE.' (Competence), and 'I feel I am rejected by those around me.' (Relatedness). In sample 2, the original items of the PNTS were used and were preceded by the stem 'in my sport...' Example items are 'I feel prevented from making choices with regard to the way I train (Autonomy), 'situations occur in which I am made to feel incapable' (Competence), and 'I feel other people dislike me' (Relatedness). The construct validity and internal reliability of the PNTS has been evidenced in previous research (Bartholomew et al. 2011a, b; Costa et al. 2015).

Students in the PE sample completed the following measure:

Behavioral regulations in physical education Students' motivational regulations were assessed using the Perceived Locus of Causality scale (PLOC: Goudas et al. 1994). Four items assessed each type of motivational regulation using a seven-point Likert scale, ranging from strongly disagree (1) to strongly agree (7), items were preceded by the stem 'I take part in PE...'. Example items include 'but I don't know why' (amotivation), 'because that is what I am supposed to do' (external), 'because I would feel bad about myself if I didn't' (introjected), 'because it is important for me to do well in PE' (identified), and 'because PE is fun' (intrinsic). The PLOC scale has evidenced acceptable levels of reliability and validity in previous research both within the UK and across cultures (Wang et al. 2009).

While athletes in the voluntary sport sample, completed the measures of:

Enjoyment The degree to which athletes experienced enjoyment during their training sessions was assessed using the seven-item Interest/Enjoyment subscale from 
the IMI (McAuley et al. 1989). The items followed the stem 'most recently I have...' and were adapted to suit the sport training and coaching context. Items were scored on a seven-point Likert scale, from strongly disagree (1) to strongly agree (7). An example item was 'found training very interesting', the IMI's subscales have exhibited acceptable construct validity and internal reliability in previous research (Tsigilis and Theodosiou 2003).

Well-being To assess the degree to which athletes felt positive energy most recently, a five-item version of the Subjective Vitality Scale (SVS; Ryan and Frederick 1997) was used. This was scored on a seven-point Likert scale, from strongly disagree (1) to strongly agree (7), with items following the stem 'most recently when doing my sport I have...'. An example item is 'felt alive and full of vitality'. The scale has demonstrated adequate construct validity and internal reliability in previous research (e.g., Gagné et al. 2003; Reinboth et al. 2004).

Burnout Athletes' symptoms of burnout were assessed using the 15-item Athlete Burnout Questionnaire (ABQ; Raedeke and Smith 2001). The measure consists of three, five-item subscales which measure physical and emotional exhaustion (e.g., 'wiped out from my sport'), reduced accomplishment (e.g., I am not achieving much in my sport') and sport devaluation (e.g., 'less concerned about being successful in my sport than I used to'). Each item followed the stem 'usually, when training for my sport with my coach I feel...' and answers were given on a five-point Likert scale of strongly disagree (1) to strongly agree (5). The scale has demonstrated adequate construct validity and internal reliability in previous research (Lemyre et al. 2007).

\section{Data analysis}

In both samples, means, standard deviations, correlations, and internal consistency estimates were computed for all study variables. Person-centred analyses were employed to examine our research question concerning the existence of different psychological need profiles. Multivariate Analysis of Variance (MANOVA) was used to explore whether experiencing different combinations of need satisfaction and need frustration had associations with the motivation, well-being, and ill-being experienced by students and athletes.

Specifically, a hierarchical cluster analysis was conducted with the whole sample to identify groups of students/athletes based on their experiences of need satisfaction and need frustration. Prior to the cluster analysis, the cases with missing data on any of the two needs were excluded (sport sample $n=2$ ). In addition, all the variables were standardized using $Z$ scores (mean of 0 and a standard deviation of 1). $Z$ scores of greater than \pm 0.5 were used as criteria to describe whether a profile scored relatively 'high' or 'low' in comparison to their peers.

For both samples, we used the hierarchical cluster method whereby each observation starts out as its own cluster. Subsequently, new clusters are formed by the combination of the most similar clusters until either all clusters are grouped into one cluster or the researcher considers that a parsimonious solution has been achieved. Ward's method was used in the hierarchical cluster analysis, as this can minimize the withincluster differences and to avoid problems with forming long, snake-like chains found in other methods (Aldenderfer and Blashfield 1984). The agglomeration schedules and dendrogram were used to determine the potential number of clusters that existed within the data. To check the replicability of the cluster solution we followed the procedures outlined in Haerens et al. (2018), we randomly split each sample (students and athletes) in half. We used the first half to determine the clusters using a k-mean clustering method with random initial seed points. For the second half, another k-mean was conducted using the centroid values obtained from the hierarchical methods as the initial seed points. The original and newly obtained clusters were compared using kappaindex. A one-way MANOVA was used to establish that the need profiles were significantly different in their experiences of need satisfaction and need frustration, while the five behavioral regulations were used to compare across the profiles to establish concurrent validity for the PE sample. For the athlete sample, a one-way MANOVA was conducted using cluster as the independent variable and the outcome variables (enjoyment, well-being, and burnout) as dependent variables. In addition, differences by gender among the clusters were examined using Chi square tests.

\section{Results}

\section{Preliminary analyses}

\section{Descriptive statistics}

Table 1 presents the means, standard deviations, internal consistency estimates, and bivariate correlations for all variables in both the PE and sport samples. For the PE sample, the mean scores for need satisfaction, need frustration, and introjected regulation were close to the scale mid-point. Mean scores for external, identified and intrinsic regulation were above the scale mid-point, while for amotivation the mean score was low. For the voluntary sport sample, mean scores for need satisfaction, enjoyment, well-being were high, and need frustration and burnout were low.

Across both samples, as expected, need satisfaction was positively correlated with autonomous motivational 
Table 1 Means, standard deviations, and correlations within each sample

\begin{tabular}{|c|c|c|c|c|c|c|c|c|c|c|}
\hline Variable & M & SD & Scale & $\propto$ & 1. & 2. & 3. & 4. & 5. & 6. \\
\hline \multicolumn{11}{|c|}{ Sample 1 physical education } \\
\hline 1. Need satisfaction & 3.85 & 1.32 & $1-7$ & .95 & - & & & & & \\
\hline 2. Need frustration & 3.37 & 1.41 & $1-7$ & .89 & $-.66^{*}$ & - & & & & \\
\hline 3. Amotivation & 2.72 & 1.62 & $1-7$ & .91 & $-.65^{*}$ & $.68^{*}$ & - & & & \\
\hline 4. External & 4.22 & 1.80 & $1-7$ & .90 & $-.33 *$ & $.42 *$ & $.59 *$ & - & & \\
\hline 5. Introjected & 3.59 & 1.34 & $1-7$ & .81 & $.23 *$ & $.01^{*}$ & -.08 & $.45^{*}$ & - & \\
\hline 6. Identified & 4.53 & 1.59 & $1-7$ & .91 & $.74 *$ & $-.60 *$ & $-.78^{*}$ & $-.39 *$ & $.33^{*}$ & - \\
\hline 7. Intrinsic & 4.41 & 1.76 & $1-7$ & .93 & $.76^{*}$ & $-.61 *$ & $-.79 *$ & $-.44 *$ & $.26^{*}$ & $.93 *$ \\
\hline Variable & M & SD & Scale & $\propto$ & 1. & & 2. & 3. & 4. & 5. \\
\hline \multicolumn{11}{|c|}{ Sample 2: voluntary leisure-time sport } \\
\hline 1. Need satisfaction & 5.53 & .63 & $1-7$ & .87 & - & & & & & \\
\hline 2. Need frustration & 2.07 & .72 & $1-7$ & .83 & $-.40 *$ & & - & & & \\
\hline 3. Enjoyment & 5.58 & .88 & $1-7$ & .89 & $.56^{*}$ & & $-.48^{*}$ & - & & \\
\hline 4. Wellbeing & 5.22 & .91 & $1-7$ & .85 & $.53^{*}$ & & $-.34 *$ & $.57 *$ & - & \\
\hline 5. Burnout & 1.76 & .58 & $1-5$ & .87 & $-.51 *$ & & $.52 *$ & $-.42 *$ & $-.49 *$ & - \\
\hline
\end{tabular}

$* \mathrm{p}<.01$

regulations and positive outcomes, and negatively correlated with controlled motivational regulations, amotivation and negative outcomes. The opposite was true for need frustration, being positively correlated with controlled motivational regulations, amotivation and negative outcomes, and negatively associated with autonomous motivational regulations and positive outcomes.

\section{Primary analyses}

\section{Identification of need profiles}

For the PE sample, the agglomeration coefficients showed that there were incremental increases from five to four clusters $(21.6 \%)$ and four to three clusters $(22 \%)$, but when three clusters were merged to two, the increase in the agglomeration coefficients was $45 \%$, therefore suggesting a threecluster solution to be suitable. The dendrogram also supported a three-cluster solution for classifying experiences of need satisfaction and need frustration. A one-way MANOVA confirmed that the profiles differed in levels of need satisfaction and need frustration, Pillai's Trace $=.845, F$ (4, $542)=99.17, p<.001, \eta^{2}=.42$. The means, standard deviations, and $\mathrm{Z}$ scores of the three profiles are shown in Table 2. With the first split-half PE sample $(\mathrm{N}=124)$, the k-means cluster analysis with free means correctly classified $90.3 \%$ of the students in the respective cluster. The second split-half with centroids obtained from the hierarchical methods used as the initial seed points, correctly classified $91.3 \%$ of the students in the original clusters. This confirmed the stability of the profiles found in the hierarchical cluster analysis.
For the sport sample, the hierarchical cluster analysis found a four-profile solution to be suitable to characterize the sample (Table 3). This was determined by the incremental percentage of the agglomeration coefficients from merging one cluster to the next. There was a small incremental increase from five to four clusters $(29.5 \%)$, but as four clusters were merged to three clusters, there was a large $(50 \%)$ increase in the coefficients, when three clusters were merged to two, the increase in the agglomeration coefficients was $58 \%$, thus showing a four cluster-solution to be suitable. The dendrogram also supported a four-cluster solution with clear equal distribution of the cases. A one-way MANOVA confirmed that the profiles differed in need satisfaction and need frustration, Pillai's Trace $=1.42, F(6,308)=127.00$, $p<.001, \eta^{2}=.71$. With the first random split-half sample $(\mathrm{N}=85)$, the $\mathrm{k}-\mathrm{means}$ cluster analysis with free means correctly classified $91.8 \%$ of the students in the respective clusters. The second split-half with centroids obtained from the hierarchical methods used as the initial seed points, correctly classified $89.0 \%$ of the athletes in the original clusters. This confirmed the stability of the profiles found in the hierarchical cluster analysis.

\section{Description of the profiles}

In both samples the first profile identified was classified as relatively 'Low Satisfaction-High Frustration' [PE $n=95$ $(34.7 \%)$; Sport $n=35$ (22.2\%)], with both students and athletes experiencing very low need satisfaction and very high need frustration. The second profile was identified as relatively 'High Satisfaction-Low Frustration' [PE n $=103$ 
Table 2 Cluster means, standard deviations, and $\mathrm{Z}$ scores for the solution of the hierarchical cluster analyses: Physical education sample

\begin{tabular}{|c|c|c|c|c|c|c|c|c|}
\hline \multirow[t]{2}{*}{ Variables } & \multicolumn{2}{|c|}{$\begin{array}{l}\text { Cluster } 1(\mathrm{~N}=95) \\
\text { 'Low S/High F' }\end{array}$} & \multicolumn{2}{|c|}{$\begin{array}{l}\text { Cluster } 2(\mathrm{~N}=103) \\
\text { 'High S/Low F' }\end{array}$} & \multicolumn{2}{|c|}{$\begin{array}{l}\text { Cluster } 3(\mathrm{~N}=76) \\
\text { 'Moderate S/Moder- } \\
\text { ate F' }\end{array}$} & \multirow[t]{2}{*}{ F Value } & \multirow[t]{2}{*}{$\eta^{2}$} \\
\hline & Mean $(Z)$ & $\mathrm{SD}$ & Mean $(Z)$ & $\mathrm{SD}$ & Mean $(Z)$ & SD & & \\
\hline \multicolumn{9}{|l|}{ Clustering dimensions } \\
\hline 1. Need Satisfaction & $2.55_{\mathrm{a}}(-.98)$ & .84 & $5.10_{\mathrm{b}}(.94)$ & .61 & $3.78_{c}(-.05)$ & .82 & $280.06^{* *}$ & .67 \\
\hline 2. Need Frustration & $4.87_{\mathrm{a}}(1.06)$ & .91 & $2.06_{b}(-.93)$ & .60 & $3.27_{\mathrm{c}}(-.07)$ & .72 & $344.55^{* *}$ & .72 \\
\hline \multicolumn{9}{|l|}{ Outcomes } \\
\hline 3. Intrinsic & $2.98_{\mathrm{a}}$ & 1.67 & $5.80_{\mathrm{b}}$ & .79 & $4.35_{c}$ & 1.28 & $117.90 * *$ & .47 \\
\hline 4. Identified & $3.20_{\mathrm{a}}$ & 1.48 & $5.74_{b}$ & .84 & $4.55_{c}$ & 1.07 & $117.53 * *$ & .47 \\
\hline 5. Introjected & $3.52_{\mathrm{a}}$ & 1.37 & $3.72_{\mathrm{a}}$ & 1.41 & $3.50_{\mathrm{a}}$ & 1.19 & .78 & $\mathrm{~ns}$ \\
\hline 6. External & $5.28_{\mathrm{a}}$ & 1.64 & $3.47_{b}$ & 1.69 & $3.96_{b}$ & 1.50 & $32.26 * *$ & .19 \\
\hline 7. Amotivation & $4.16_{\mathrm{a}}$ & 1.65 & $1.56_{\mathrm{b}}$ & .60 & $2.48_{c}$ & 1.03 & $123.24 * *$ & .48 \\
\hline 8. Gender (\% Male) & 33.7 & & 67.0 & & 44.7 & & & \\
\hline
\end{tabular}

Cluster descriptions are relative to one another in the sample. ${ }^{*} p<.05, * * p<.01$. Means in the same row that do not share subscripts differed at $p<.05$ using Tukey's HSD

Table 3 Cluster means, standard deviations, and Z scores for the solution of the hierarchical cluster analyses: Sport sample

\begin{tabular}{|c|c|c|c|c|c|c|c|c|c|c|}
\hline \multirow[t]{2}{*}{ Variables } & \multicolumn{2}{|c|}{$\begin{array}{l}\text { Cluster } 1(\mathrm{~N}=35) \text { 'Low } \\
\text { S/High F' }\end{array}$} & \multicolumn{2}{|c|}{$\begin{array}{l}\text { Cluster } 2(\mathrm{~N}=31) \text { 'High } \\
\text { S/Low F' }\end{array}$} & \multicolumn{2}{|c|}{$\begin{array}{l}\text { Cluster } 3 \\
(\mathrm{~N}=49)^{`} \text { Mod S/Low } \\
\mathrm{F}^{\prime}\end{array}$} & \multicolumn{2}{|c|}{$\begin{array}{l}\text { Cluster } 4(\mathrm{~N}=43) \\
\text { 'Mod S/High F' }\end{array}$} & \multirow[t]{2}{*}{ F value } & \multirow[t]{2}{*}{$\eta^{2}$} \\
\hline & Mean $(\mathrm{Z})$ & SD & Mean $(Z)$ & SD & Mean $(Z)$ & $\mathrm{SD}$ & Mean $(\mathrm{Z})$ & SD & & \\
\hline \multicolumn{11}{|l|}{ Clustering dimensions } \\
\hline 1. Need Satisfaction & $4.66_{\mathrm{a}}(-1.38)$ & .35 & $6.26_{\mathrm{b}}(1.15)$ & .26 & $5.42_{c}(-.18)$ & .28 & $5.85_{\mathrm{d}}(.50)$ & .33 & $171.02 * *$ & .77 \\
\hline 2. Need Frustration & $2.73_{\mathrm{a}}(.90)$ & .38 & $1.23_{\mathrm{b}}(-1.16)$ & .22 & $1.64_{\mathrm{c}}(-.59)$ & .31 & $2.64_{a}(.78)$ & .52 & $136.42 * *$ & .73 \\
\hline \multicolumn{11}{|l|}{ Outcomes } \\
\hline 3. Enjoyment & $5.02_{\mathrm{a}}$ & .86 & $6.46_{\mathrm{b}}$ & .39 & $5.49_{\mathrm{c}}$ & .89 & $5.49_{\mathrm{c}}$ & .67 & $21.27 * *$ & .29 \\
\hline 4. Well-being & $4.62_{\mathrm{a}}$ & 1.09 & $5.93_{\mathrm{b}}$ & .72 & $5.20_{\mathrm{c}}$ & .70 & $5.25_{\mathrm{c}}$ & .75 & $14.17 * *$ & .22 \\
\hline 5. Burnout & $2.33_{\mathrm{a}}$ & .63 & $1.43_{\mathrm{b}}$ & .49 & $1.54_{b}$ & .36 & $1.79_{\mathrm{b}}$ & .48 & $23.92 * *$ & .32 \\
\hline 6. Gender (\% Male) & 54.3 & & 45.2 & & 40.8 & & 44.2 & & & \\
\hline
\end{tabular}

Cluster descriptions are relative to one another in the sample. ${ }^{*} p<.05,{ }^{* *} p<.01$. Means in the same row that do not share subscripts differed at $p<.05$ using Tukey's HSD

(37.6\%); Sport $n=31(19.6 \%)]$. As the label suggests these students and athletes had very high need satisfaction and very low need frustration. In the PE sample, the third profile was characterized by moderate experiences of both need satisfaction and need frustration and was classified as relatively 'Moderate Satisfaction-Moderate Frustration' $[n=76$ $(27.7 \%)]$. However, in the sport sample two profiles emerged that were characterized by moderate experiences of need satisfaction but differed on experiences of need frustration. Athletes in the third profile had moderate experiences of need satisfaction and low need frustration and were identified as relatively 'Moderate Satisfaction-Low Frustration' $[n=49(31.0 \%)]$. Whereas, athletes in the fourth profile had moderate experiences of need satisfaction and high need frustration and were classified as relatively 'Moderate Satisfaction-High Frustration' [n=43 (27.2\%)]. There were significant differences in gender distribution for the PE sample among the three profiles $\left(\chi_{(2)}^{2}=22.80, p<.001\right)$, but not for the sport sample $(p>.05)$.

\section{Exploring differences in need profiles}

The results of the one-way MANOVAs with cluster (from the hierarchical cluster analysis) as the independent variable and the five behavioral regulations (PE) or four outcomes (sport) as dependent variables showed a significant multivariate effect (PE: Pillai's Trace $=.58, F(10$, 536) $=21.71, p<.001, \eta^{2}=.29$; Sport: Pillai's Trace $=.534$, $\left.F(12,459)=8.28, p<.001, \eta^{2}=.18\right)$. Follow-up ANOVAs Tukey's honestly significant difference (HSD) tests revealed significant differences across the three PE profiles in all the behavioral regulations, except for introjected regulation and 
across the four sport profiles for all outcome variables. As shown in Table 2, pairwise comparisons revealed significant differences between two clusters for most of the behavioural regulations, except introjected regulation. However, there were no differences in the pairwise comparisons in external regulation between the 'Moderate Satisfaction-Moderate Frustration' and 'High Satisfaction-Low Frustration' profiles. The pairwise comparisons for the sport sample are presented in Table 3 and show that the 'High Satisfaction-Low Frustration' cluster scored high in enjoyment and well-being compared to the other three clusters and lower in burnout compared to the 'Low Satisfaction-High Frustration' cluster. The athletes from the 'Moderate Satisfaction-Low Frustration' profile and 'Moderate Satisfaction-High Frustration' did not differ in any of the four outcomes.

In both samples, the most adaptive profile was the 'High Satisfaction-Low Frustration' profile with students and athletes reporting high scores for intrinsic and identified regulations, enjoyment and well-being and low scores for external regulation, amotivation, and burnout. The least adaptive profile was the 'Low Satisfaction-High Frustration' profile with students and athletes reporting very high scores for amotivation, and high external regulation and burnout, and very low scores for identified and intrinsic regulation, and low enjoyment and well-being.

\section{Discussion}

The current study explored the combined relationships between need satisfaction and need frustration and their simultaneous associations with motivation and psychological health within two physical activity contexts. Although there is considerable evidence across the BPNT literature to support the distinctiveness of need satisfaction and need frustration (see Vansteenkiste and Ryan 2013), this study provides an insight into the combined effects of these distinct constructs. We established the co-occurring nature of the psychological needs in two separate contexts, through identifying subgroups characterized by different combinations of need satisfaction and need frustration (psychological need profiles). Moreover, we were able to demonstrate that the different psychological need profiles had unique associations with motivation, well-being, and ill-being. We therefore extend the existing literature on psychological need experiences by (1) providing empirical evidence for the distinct, yet co-occurring, nature of need satisfaction and need frustration, (2) providing evidence to support the proposed asymmetrical relationship between low need satisfaction and need frustration, and (3) demonstrating the importance of the combined, rather than separate, associations of need satisfaction and need frustration with motivation and psychological health.

\section{Psychological need profiles as distinct, yet co-occurring constructs}

We found evidence in both samples of the distinct, yet co-occurring, nature of need satisfaction and need frustration. The emergence of more than two profiles that were not simply characterized by opposite experiences of need satisfaction and need frustration (e.g., high-low and low-high) suggested that individuals' were reporting that they simultaneously experienced both need frustration and need satisfaction during the course of a typical PE lesson or training session. Moreover, the modest to strong negative correlations which are consistent with those reported in previous literature support the distinct nature of need satisfaction and need frustration and their potential to cooccur (e.g., Bartholomew et al. 2011a, b; Haerens et al. 2015). Although the voluntary sport setting provided a more nuanced set of findings in terms of identifying one more profile than the PE sample, the outcomes associated with the profiles suggests that there was a degree of stability and generalizability of the profiles in the two contexts. This occurred despite large variations in the experiences of need satisfaction and need frustration between the two contexts.

In both contexts, support was also found for the proposed asymmetrical relationship between need satisfaction and need frustration (Vansteenkiste and Ryan 2013) since a 'High Satisfaction-High Frustration' profile did not emerge. Instead, in the sport sample a 'Moderate Satisfaction-Low Frustration' and 'Moderate Satisfaction-High Frustration' profile emerged while in the PE a 'Moderate' profile was evident. The profiles identified in our samples suggest that experiencing need frustration within a context may prevent high need satisfaction being experienced. For example, when need frustration was moderate or high only low or moderate levels of need satisfaction were experienced, whereas when need frustration was not experienced, need satisfaction was experienced to at least moderate levels. These are potentially important implications given the considerable evidence across all life domains associating experiences of need satisfaction with optimal functioning (Mouratidis et al. 2011; Milyavskaya and Koestner 2011; Reeve and Jang 2006; Van den Broeck et al. 2010; Williams et al. 2011) and experiences of need frustration with deleterious effects (Bartholomew et al. 2011a, b, 2018; Costa et al. 2014, 2015; Halvari et al. 2017; Haerens et al. 2015; Olafsen et al. 2017). Moreover, this occurs even when in absolute terms the average need frustration for the sport sample is low in relation to the seven-point measurement scale. 


\section{Psychological need profiles: associations with motivation and psychological health}

Unique associations, that were consistent with our hypotheses, emerged between the different need profiles and students' and athletes' motivation, well-being, and ill-being. These highlighted the role of need satisfaction and need frustration in leading the association of the profiles with the outcomes. In both samples, individuals in profiles characterized by opposites in need satisfaction and frustration reported more optimal outcomes when need satisfaction was high (High Satisfaction-Low Frustration) and less optimal outcomes when need frustration was high (Low SatisfactionHigh Frustration). These findings are consistent with the established literature on the distinct effects of need frustration and need satisfaction (e.g., Bartholomew et al. 2011b; Vansteenkiste and Ryan 2013). Despite this clear pattern between the adaptive and maladaptive profiles characterized by either need satisfaction or need frustration, in the PE sample our findings suggest that introjected regulation is associated with both need satisfaction and need frustration. This is consistent with previous research which has shown the introjected regulation of competitive swimmers (Pelletier et al. 2001) and adolescents participating in PE class (Haerens et al. 2015) to be significantly associated with constructs in both the bright and dark motivational pathway.

Although the 'High Satisfaction-Low Frustration' profile was the most adaptive profile in both samples there was evidence in the more nuanced set of profiles that emerged in the sport sample for the potential countering effects of need satisfaction. The variable-centered literature overwhelmingly attests to the detrimental effects of experiences of need frustration (e.g., Bartholomew et al. 2011a, b, 2014; Chen et al. 2015; Costa et al. 2014; Jang et al. 2016; Stebbings et al. 2012; Teixeria et al. 2018), however our person-centered analyses reveal that these can be affected by concomitant experiences of need satisfaction. Specifically, we found that when experiences of need satisfaction were moderate, experiences of need frustration appeared to be less detrimental to the outcomes reported by athletes. To illustrate this, a comparison of the outcomes of the 'Low Satisfaction-High Frustration' and 'Moderate Satisfaction-High Frustration' profiles revealed that despite experiencing need frustration athletes experienced less burnout and more enjoyment and higher well-being when need satisfaction was also experienced. Moreover, this effect was also evidenced at different levels of need frustration when similar experiences of need satisfaction (as indicated by the labels for the profiles) occurred. There was no difference in the outcomes experienced in the 'Moderate-Satisfaction-High Frustration' and the 'Moderate Satisfaction-Low Frustration' profiles, despite one set of athletes experiencing need frustration. Although it should be noted that despite the similar 'moderate' labels, the athletes in the latter profile experienced higher need satisfaction scores than those in the former profile, which may account for the lack of difference in outcomes. However, collectively, our results suggest that concurrent experiences of need satisfaction are critical to people's optimal and nonoptimal functioning, especially when need frustration is experienced. However, there may be limits to this protective effect of experiences of need satisfaction since athletes in all other profile combinations did not fare as well in outcome experiences as athletes in the 'High Satisfaction-Low Frustration' profile.

\section{Limitations and future research}

This study makes an important and unique contribution to the motivation literature by providing an insight into the combined relations between need satisfaction and need frustration and their associations with motivation and psychological health. However, further research in different life domains is needed to corroborate and extend the findings on this fundamental and understudied issue. Future research may also wish to address the limitations of the current study which include its cross-sectional design and reliance on domain specific self-report measures. Such work may wish to employ domain general measures (e.g., those by Chen et al. 2015 and Sheldon and Hilpert 2012) to assess need satisfaction and need frustration and utilize objective measures of outcomes. Moreover, it may wish to consider whether analyzing profiles of the separate needs of competence, autonomy, and relatedness, rather than at a global level as in the current study, in relation to their satisfaction and frustration would be fruitful. Theoretical propositions indicate that all three psychological needs are equally important for optimal functioning (Deci and Ryan 2000), but it is possible that the satisfaction or frustration of a particular need is more or less damaging to the outcomes experienced by an individual. Employing person-centered analyses at the specific need level would provide important empirical support for this theoretical proposition and combining this with a withinperson perspective could examine whether the nature of the context (compulsory versus voluntary) is influential. Once the psychological need profiles have been corroborated in different life domains it would also be beneficial to examine them in the context of the sequence of the bright and dark motivational pathways. This would enable us to ascertain the nomological network associated with the psychological need profiles. Future research may also wish to consider the longitudinal examination of need profiles and draw from the longitudinal Growth Mixture Analysis work on psychological needs (e.g., Gillet et al. 2017; Ratelle and Duchesne 2014) to explore if and how profile membership changes over time and the antecedents and outcomes associated with such changes. These areas provide interesting opportunities 
for the future that will develop our conceptual and practical understanding of psychological need experiences.

In summary, the emergence of distinct need profiles supports the proposition that need satisfaction and need frustration are best viewed as separate and distinct, yet co-occurring, constructs. It is important to consider the combined associations of need satisfaction and need frustration since there was evidence of a protective effect of experiences of need satisfaction when individuals experienced need frustration. Consequently, this concurrent view of psychological needs provides a more nuanced understanding of people's optimal and non-optimal functioning. Our study emphasizes the importance of exploring these interesting and influential combinations of need experiences in greater detail if we are to fully understand their associations with optimal and nonoptimal functioning.

\section{Compliance with ethical standards}

Conflict of interest All authors declare that they have no conflict of interest.

Ethical approval All procedures performed in studies involving human participants were in accordance with the ethical standards of the institutional research committee of the lead author and with the 1964 Helsinki declaration and its later amendments or comparable ethical standards.

Informed consent Informed consent was obtained from all individual participants included in the studies.

Open Access This article is distributed under the terms of the Creative Commons Attribution 4.0 International License (http://creativeco mmons.org/licenses/by/4.0/), which permits unrestricted use, distribution, and reproduction in any medium, provided you give appropriate credit to the original author(s) and the source, provide a link to the Creative Commons license, and indicate if changes were made.

\section{References}

Adie, J. W., Duda, J. L., \& Ntoumanis, N. (2008). Autonomy support, basic need satisfaction and the optimal functioning of adult male and female sport participants: A test of basic needs theory. Motivation and Emotion, 32, 189-199. https://doi.org/10.1007/s1103 1-008-9095-z.

Aldenderfer, M. S., \& Blashfield, R. K. (1984). Cluster analysis. Newbury Park, CA: Sage Publications.

Bartholomew, K. J., Ntoumanis, N., Cuevas, R., \& Lonsdale, C. (2014). Job pressure and ill-health in physical education teachers: The mediating role of psychological need thwarting. Teaching and Teacher Education, 37, 101-107. https://doi.org/10.1016/j. tate.2013.10.006.

Bartholomew, K. J., Ntoumanis, N., Mouratidis, A., Katartzi, E., Thøgersen-Ntoumani, C., \& Vlachopoulos, S. (2018). Beware of your teaching style: A school-year long investigation of controlling teaching and student motivational experiences. Learning and Instruction, 53, 50-63. https://doi.org/10.1016/j.learninstr uc.2017.07.006.

Bartholomew, K. J., Ntoumanis, N., Ryan, R. M., Bosch, J. A., \& Thøgersen-Ntoumani, C. (2011a). Self-determination theory and diminished functioning: The role of interpersonal control and psychological need thwarting. Personality and Social Psychology Bulletin, 37, 1459-1503. https://doi.org/10.1177/0146167211 413125.

Bartholomew, K. J., Ntoumanis, N., Ryan, R. M., \& ThøgersenNtoumani, C. (2011b). Psychological need thwarting in the sport context: Assessing the darker side of athletic experience. Journal of Sport and Exercise Psychology, 33, 75-102. https:// doi.org/10.1123/jsep.33.1.75.

Bartholomew, K. J., Ntoumanis, N., \& Thøgersen-Ntoumani, C. (2009). A review of controlling motivational strategies from a self-determination theory perspective: Implications for sports coaches. International Review of Sport and Exercise Psychology, 2, 215-233. https://doi.org/10.1080/17509840903235330.

Campbell, R., Boone, L., Vansteenkiste, M., \& Soenens, B. (2018). Psychological need frustration as a transdiagnostic process in associations of self-critical perfectionism with depressive symptoms and eating pathology. Journal of Clinical Psychology, 74, 1775-1790. https://doi.org/10.1002/jclp.2018.74.issue-10.

Chen, B., Vansteenkiste, M., Beyers, W., Boone, L., Deci, E. L., Van der Kaap-Deeder, J., et al. (2015). Basic psychological need satisfaction, need frustration, and need strength across four cultures. Motivation and Emotion, 39, 216-236. https:// doi.org/10.1007/s11031-014-9450-1.

Costa, S., Coppolino, P., \& Oliva, P. (2015). Exercise dependence and maladaptive perfectionism: The mediating role of basic psychological needs. International Journal of Mental Health Addiction, 14, 241-256. https://doi.org/10.1007/s11469-015-9586-6.

Costa, S., Ntoumanis, N., \& Bartholomew, K. J. (2014). Predicting the brighter and darker sides of interpersonal relationships: Does psychological need thwarting matter? Motivation and Emotion, 39, 11-24. https://doi.org/10.1007/s1103 1-014-9427-0.

Deci, E. L., \& Ryan, R. M. (1985). Intrinsic motivation and self-determination in human behavior. New York: Plenum.

Deci, E. L., \& Ryan, R. M. (2000). The "what" and "why" of goal pursuits: Human needs and the self-determination of behavior. Psychological Inquiry, 11, 227-268. https://doi.org/10.1207/ S15327965PLI1104_01.

Gagné, M., Ryan, R. M., \& Bargmann, K. (2003). The effects of parent and coach autonomy support and need satisfaction in the motivation and well-being of gymnasts. Journal of Applied Sport Psychology, 15, 372-390. https://doi.org/10.1080/714044203.

Gillet, N., Morin, A. J. S., Huyghebaert, T., Burger, L., Maillot, A., Poulin, A., et al. (2017). University students' need satisfaction trajectories: A growth mixture analysis. Learning and Instruction. https://doi.org/10.1016/j.learninstruc.2017.11.003.

Goudas, M., Biddle, S., \& Fox, K. (1994). Perceived locus of causality, goal orientations, and perceived competence in school physical education classes. British Journal of Educational Psychology, 64, 453-463. https://doi.org/10.1111/j.2044-8279.1994.tb01116.x.

Haerens, L., Aelterman, N., Vansteenkiste, M., Soenens, B., \& Van Petegem, S. (2015). Do perceived autonomy-supportive and controlling teaching relate to physical education students' motivational experiences through unique pathways? Distinguishing between the bright and dark side of motivation. Psychology of Sport and Exercise, 16, 26-36. https://doi.org/10.1016/j.psych sport.2014.08.013.

Haerens, L., Vansteenkiste, M., De Meester, A., Delrue, J., Tallir, I., Vande Broek, G., et al. (2018). Different combinations of perceived autonomy support and control: Identifying the most 
optimal motivating style. Physical Education and Sport Pedagogy, 23, 16-36. https://doi.org/10.1080/17408989.2017.1346070.

Halvari, A. E. M., Halvari, H., Bjørnebekk, G., \& Deci, E. L. (2013). Oral health and dental well-being: Testing a self-determination theory model. Journal of Applied Social Psychology, 43, 275-292. https://doi.org/10.1111/j.1559-1816.2012.00996.x.

Halvari, A. E. M., Halvari, H., Williams, G. C., \& Deci, E. L. (2017). Predicting dental attendance from dental hygienists' autonomy support and patients' autonomous motivation: A randomised clinical trial. Psychology \& Health, 32, 127-144. https://doi. org/10.1080/08870446.2016.1244536.

Jang, H., Kim, E. J., \& Reeve, J. (2016). Why students become more engaged or more disengaged during the semester: A self-determination theory dual-process model. Learning and Instruction, 43, 27-38. https://doi.org/10.1016/j.learninstruc.2016.01.002.

Lemyre, P. N., Roberts, G. C., \& Stray-Gundersen, J. (2007). Motivation, overtraining, and burnout: Can self-determined motivation predict overtraining and burnout in elite athletes? European Journal of Sport Science, 7, 115-126. https://doi.org/10.1080/17461 390701302607.

Mabbe, E., Soenens, B., Vansteenkiste, M., van der Kaap-Deeder, J., \& Mouratidis, A. (2018). Day-to-day variation in autonomysupportive and psychologically controlling parenting: The role of parents' daily experiences of need satisfaction and need frustration. Parenting, 18(2), 86-109. https://doi.org/10.1080/15295 192.2018.1444131.

Markland, D., \& Tobin, V. J. (2010). Need support and behavioural regulations for exercise among exercise referral scheme clients: The mediating role of psychological need satisfaction. Psychology of Sport and Exercise, 11, 91-99. https://doi.org/10.1016/j.psych sport.2009.07.001.

McAuley, E., Duncan, T., \& Tammen, V. V. (1989). Psychometric properties of the intrinsic motivation inventory in a competitive sport setting: A confirmatory factor analysis. Research Quarterly for Exercise and Sport, 60, 48-58. https://doi.org/10.1080/02701 367.1989.10607413.

Milyavskaya, M., \& Koestner, R. (2011). Psychological needs, motivation, and well-being: A test of self-determination theory across multiple domains. Personality and Individual Differences, 50, 387-391. https://doi.org/10.1016/j.paid.2010.10.029.

Morin, A. J. S., \& Wang, C. K. J. (2015). A gentle introduction to mixture modeling using physical fitness performance data. In $\mathrm{N}$. Ntoumanis \& N. Myers (Eds.), An introduction to intermediate and advanced statistical analyses for sport and exercise scientists (pp. 183-210). Chichester: Wiley.

Mouratidis, A. A., Vansteenkiste, M., Sideridis, G., \& Lens, W. (2011). Vitality and interest-enjoyment as a function of class-to-class variation in need-supportive teaching and pupils' autonomous motivation. Journal of Educational Psychology, 103, 353-366. https:// doi.org/10.1037/a0022773.

Ntoumanis, N. (2002). Motivational clusters in a sample of British physical education classes. Psychology of Sport and Exercise, 3, 177-194. https://doi.org/10.1016/S1469-0292(01)00020-6.

Olafsen, A. H., Niemiec, C. P., Halvari, H., Deci, E. L., \& Williams, G. C. (2017). On the dark side of work: A longitudinal analysis using self-determination theory. European Journal of Work and Organizational Psychology, 26, 275-285. https://doi.org/10.1080/13594 32X.2016.1257611.

Patrick, H., Knee, C. R., Canevello, A., \& Lonsbary, C. (2007). The role of need fulfillment in relationship functioning and wellbeing: A self-determination theory perspective. Journal of Personality and Social Psychology, 92, 434-457. https://doi. org/10.1037/0022-3514.92.3.434.

Pelletier, L. G., Fortier, M. S., Vallerand, R. J., \& Briere, N. M. (2001). Associations among perceived autonomy support, forms of self-regulation, and persistence: A prospective study. Motivation and Emotion, 25, 279-306. https://doi.org/10.1023/A:10148 05132406.

Quested, E., \& Duda, J. L. (2010). Exploring the social-environmental determinants of well- and ill-being in dancers: A test of Basic Needs Theory. Journal of Sport and Exercise Psychology, 32, 39-60. https://doi.org/10.1123/jsep.32.1.39.

Raedeke, T. D., \& Smith, A. L. (2001). Development and preliminary validation of an athlete burnout questionnaire. Journal of Sport \& Exercise Psychology, 23, 281-306. https://doi.org/10.1123/ jsep.23.4.281.

Ratelle, C. F., \& Duchesne, S. (2014). Trajectories of psychological need satisfaction from early to late adolescence as a predictor of adjustment in school. Contemporary Educational Psychology, 39, 388-400. https://doi.org/10.1016/j.cedpsych.2014.09.003.

Reeve, J., \& Jang, H. (2006). What teachers say and do to support students' autonomy during a learning activity. Journal of Educational Psychology, 98, 209-218. https://doi. org/10.1037/0022-0663.98.1.209.

Reinboth, M., Duda, J. L., \& Ntoumanis, N. (2004). Dimensions of coaching behavior, need satisfaction, and the psychological and physical welfare of young athletes. Motivation and Emotion, 28, 297-313. https://doi.org/10.1023/B:MOEM.0000040156.81924 .b8.

Richer, S., \& Vallerand, R. J. (1998). Construction and validation of the perceived relatedness scale. European Review of Applied Psychology, 48, 129-137.

Ryan, R. M., \& Deci, E. L. (2000). The darker and brighter sides of human existence: Basic psychological needs as a unifying concept. Psychological Inquiry, 11, 319-338. https://doi.org/10.1207/ S15327965PLI1104 03.

Ryan, R. M., \& Deci, E. L. (2002). Overview of Self-Determination Theory: An organismic dialectical perspective. In E. L. Deci \& R. M. Ryan (Eds.), Handbook of self-determination research (pp. 3-33). New York: The University of Rochester Press.

Ryan, R. M., Deci, E. L., \& Vansteenkiste, M. (2016). Autonomy and autonomy disturbances in self-development and psychopathology: Research on motivation, attachment, and clinical process. In D. Cicchetti (Ed.), Developmental psychopathology (3rd ed., pp. 385-438). Hoboken: Wiley. https://doi.org/10.1002/9781119125 556.devpsy 109 .

Ryan, R. M., \& Frederick, C. (1997). On energy, personality and health: Subjective vitality as a dynamic reflection of wellbeing. Journal of Personality, 65, 529-565. https://doi. org/10.1111/j.1467-6494.1997.tb00326.x.

Sheldon, K. M., \& Hilpert, J. C. (2012). The balanced measure of psychological needs (BMPN) scale: An alternative domain general measure of need satisfaction. Motivation and Emotion, 36, 439-451. https://doi.org/10.1007/s11031-012-9279-4.

Smoll, F. L., \& Smith, R. E. (2002). Coaching behavior research and intervention in youth sports. In F. L. Smoll \& R. E. Smith (Eds.), Children and youth in sport: A biopsychosocial perspective (2nd ed.). Dubuque, IA: Kendall/Hunt.

Soenens, B., Sierens, E., Vansteenkiste, M., Dochy, F., \& Goossens, L. (2012). Psychologically controlling teaching: Examining outcomes, antecedents, and mediators. Journal of Educational Psychology, 104, 108-120. https://doi.org/10.1037/a0025742.

Standage, M., Duda, J. L., \& Ntoumanis, N. (2003). A model of contextual motivation in physical education: Using constructs from self-determination and achievement goal theories to predict physical activity intentions. Journal of Educational Psychology, 95, 97-110. https://doi.org/10.1037/0022-0663.95.1.97.

Stebbings, J., Taylor, I. M., Spray, C. M., \& Ntoumanis, N. (2012). Antecedents of perceived coach interpersonal behaviors: The coaching environment and coach psychological well- and 
ill-being. Journal of Sport \& Exercise Psychology, 34, 481-502. https://doi.org/10.1123/jsep.34.4.481.

Teixeira, D. S., Silva, M. N., \& Palmeira, A. L. (2018). How does frustration make you feel? A motivational analysis in exercise context. Motivation and Emotion. https://doi.org/10.1007/s1103 1-018-9690-6.

Tsigilis, N., \& Theodosiou, A. (2003). Temporal stability of the intrinsic motivation inventory. Perceptual and Motor Skills, 97, 271280. https://doi.org/10.2466/pms.2003.97.1.271.

Van den Broeck, A., Vansteenkiste, M., De Witte, H., Soenens, B., \& Lens, W. (2010). Capturing autonomy, competence, and relatedness at work: Construction and initial validation of the work-related basic need satisfaction scale. Journal of Occupational and Organizational Psychology, 83, 981-1002. https://doi. org/10.1348/096317909X481382.

Van Der Kaap-Deeder, J., Soenens, B., Mabbe, E., Dieleman, L., Mouratidis, A., Campbell, R., et al. (2019). From daily need experiences to autonomy-supportive and psychologically controlling parenting via psychological availability and stress. Parenting, 19, 177-202. https://doi.org/10.1080/15295192.2019.1615791.

Vansteenkiste, M., \& Ryan, R. M. (2013). On psychological growth and vulnerability: Basic psychological need satisfaction and need frustration as a unifying principle. Journal of Psychotherapy Integration, 23, 263-280. https://doi.org/10.1037/a0032359.

Vansteenkiste, M., Sierens, E., Soenens, B., Luyckx, K., \& Lens, W. (2009). Motivational profiles from a self-determination perspective: The quality of motivation matters. Journal of Educational Psychology, 101, 671-688. https://doi.org/10.1037/a0015083.
Wang, C. K. J., \& Biddle, S. J. H. (2001). Young people's motivational profiles in physical activity: A cluster analysis. Journal of Sport \& Exercise Psychology, 23, 1-22. https://doi.org/10.1123/ jsep.23.1.1.

Wang, J. C. K., Hagger, M., \& Liu, W. C. (2009). A cross-cultural validation of perceived locus of causality scale in physical education context. Research Quarterly for Exercise and Sport, 80, 313-325. https://doi.org/10.1080/02701367.2009.10599566.

Wang, C. K. J., Morin, A. J. S., Liu, W. C., \& Chian, L. K. (2016). Predicting physical activity intention and behaviour using achievement goal theory: A person-centred analysis. Psychology of Sport and Exercise, 23, 13-20. https://doi.org/10.1016/j.psychsport .2015.10.004.

Williams, G. C., Patrick, H., Niemiec, C. P., Ryan, R. M., Deci, E. L., \& Lavigne, H. M. (2011). The smoker's health project: A selfdetermination theory intervention to facilitate maintenance of tobacco abstinence. Contemporary Clinical Trials, 32, 535-543. https://doi.org/10.1016/j.cct.2011.03.002.

Publisher's Note Springer Nature remains neutral with regard to jurisdictional claims in published maps and institutional affiliations. 